\title{
Quality by design-based evaluation and optimization of ceftibuten flexible dispersible tablet design with high drug loading using Design-Expert software
}

\author{
Saravana Perumal GOVINDAN 1 * (D), Senthamarai RAJAGOPALAN 2 (D), Anbarasu KUMAR ${ }^{3}$ (D) \\ 1 Research Scholar, Department of Biotechnology, PMIST, Vallam, Thanjavur (Tamil Nadu) - 613403, India \\ 2 Principal, Periyar College of Pharmaceutical Sciences, Tiruchirappalli-620021, (Tamil Nadu)-620021, India \\ 3 Assistant Professor, Department of Biotechnology, PMIST, Vallam, Thanjavur (Tamil Nadu) - 613403, India \\ * Corresponding Author. Email: gsaravana23@yahoo.co.in (G.S.); Tel. +91-917 6211909.
}

Received: 29 November 2020 / Revised: 21 February 2021 / Accepted: 01 April 2021

\begin{abstract}
There are challenges in developing dispersible tablets with a high drug loading of a waterinsoluble drug having flexibility, either as dispersible in water or as dispersible in the oral cavity before swallowing with overall acceptability. Overall acceptability is determined by the characteristics of the drug product and user acceptance. This study aimed to design and optimise the flexible dispersible tablets design using a model drug, namely ceftibuten with the drug loading of about $72 \% \mathrm{w} / \mathrm{w}$ of targeted tablet weight, in a statistically significant manner using design-expert software. The significant effects of screened input parameters on target responses were characterised based on the half-normal plot for the magnitude of effects, pareto chart for standardised effects, and variance analysis for the statistically significant model. The characterised design was optimised using the response surface method (RSM). The optimised target response was statistically confirmed based on the extent of statistical significance (very significant $<0.01$, significant $<0.05$ but $>0.01$ ). Among the input factors studied, crospovidone concentration shows a statistically very significant effect $(<0.0001)$ on target response namely in vitro disintegration time, in vivo disintegration time, and overall acceptability of intended flexible dispersible tablet design. The outcome of designed and evaluated flexible dispersible tablets (FDT) using design-expert software demonstrated its ability to predict the design space with a statistical significance, which maximises the robust product characteristics and overall user acceptance.
\end{abstract}

KEYWORDS: Quality by design; design of experiments; ceftibuten; flexible dispersible tablet; high drug loading; user acceptance testing; design-expert software.

\section{INTRODUCTION}

Globally, irrespective of age groups, the most alarming factors affecting the betterment of therapeutic outcomes are swallowing difficulty, chewing difficulty, and dry mouth condition. Several factors include the size of the dosage form, ageing process, oral health problems, cognitive impairment, and impaired salivary secretion that could have an impact on the above-said conditions [1-3]. As notified by the world health organization (WHO), flexible solid dosage forms are likely to prove most suitable for global use, including in developing countries. As defined by the world health organization (WHO), flexible solid dosage form are a solid dosage form that can be administered to patients in more than one manner, for example, the dosage form can be taken orally either as dispersed in water or as an orally dispersible [4]. To overcome the above-said alarming factors, flexible dispersible formulation remains a choice to ease dosage form administration [5-9].

The quality of a drug product is defined as the suitability of a designed drug product for its intended application. As addressed by the United States Food and Drug Administration (US-FDA) and the European Medicines Agency (EMEA), it is necessary to identify those attributes that are critical to the quality of the drug product taking into consideration of intended usage, target population, and route of administration. Traditionally quality of drug products is ensured through in process controls at several stages and further through finished product release testing [9]. However, in the modern context of the pharmaceutical drug

How to cite this article: Govindan SP, Senthamarai R, Anbarasu K. Quality by design-based evaluation and optimization of ceftibuten flexible dispersible tablet design with high drug loading using Design-Expert software. J Res Pharm. 2021; 25(3): 341-351. 
product development, the quality of drug product ensured through a quality risk assessment approach called quality by design $(\mathrm{QbD})$, a systematic approach to drug product design with a set of quality characteristic linked to the safety of the targeted population, derived from quality target profile (QTPP) and critical quality attributes (CQAs) [9-12].

The statistical elements of $\mathrm{QbD}$ are described as the design of experiments (DOE), a systematic approach to carrying out the experiments using DOE software, ensuring the data generated and derived conclusions are statistically valid. DOE having widespread applications in the pharmaceutical industry. Traditionally, screening, characterisation, and optimisation of experiments were carried out based on the scenario of the one factor effect (input) at a time on the targeted response (output). However, this traditional experiment design method has several demerits such as time-consuming, inability to address the extent of variability in the experimentation, and not cost-effective and statistically sound. On the other hand, experimentation using DOE software can handle multiple factors in a single run [11,17]. Depending upon the objectives of the experiment (screening/characterisation and optimisation), the number of factors involved and method of an evaluation required i.e. whether a single factor impact understanding or multiple factors order of interaction (input) on the targeted response (output), experiments shall be designed accordingly using DOE software. After narrow downing the input factors, further optimisation was carried out to a well-defined operating range zone. It dictates that factors within the zone can produce quality drug products consistently and play a crucial role in continuous quality improvement as part of global regulatory requirements.

The model drug chosen is Ceftibuten, a third-generation cephalosporin approved globally in a conventionally sized capsule for adults and powder for oral suspension for the paediatrics and geriatrics population. Ceftibuten is practically insoluble in water and the highest dose of drug exhibits high solubility from $\mathrm{pH} 6.5$ aqueous buffer. Based on the literature review, $\mathrm{pH}$ 7.0-7.4 phosphate buffer is recommended for quality control release media [18-19]. Ceftibuten is rapidly absorbed from the capsule with a Tmax of $2.6 \mathrm{~h}$ and from powder for oral suspension with a Tmax of $2.0 \mathrm{~h}$ after oral administration under fasting condition. The plasma concentration of ceftibuten is dose-proportional following a single dose of $200 \mathrm{mg}$ and $400 \mathrm{mg}$ capsule, and powder for oral suspension between $4.5 \mathrm{mg} / \mathrm{kg}$ and $9 \mathrm{mg} / \mathrm{kg}$. The capsule and powder for oral suspension dosage formulations of ceftibuten are bioequivalent to each other. Ceftibuten is excreted in the urine. Ceftibuten is $65 \%$ bound to plasma proteins, the protein binding is independent of plasma ceftibuten concentration [20]. The ceftibuten powder for oral suspension dosage form possesses potential advantages in the condition of swallowing difficulty. However, shorter shelf-life and recommended special storage condition after reconstitution reduces its potential applications [8]. The above potential disadvantages stress the importance of designing a novel formulation found to be acceptable across the age groups in the condition of swallowing difficulty, chewing difficulty, dry mouth (deficient of salivary secretion), and non-availability of good quality potable water. As addressed earlier, flexible dispersible formulation remains the best choice suits to comply with the above needs globally. Due to the high drug content of the intended dosage form design and the water insoluble nature of the model drug, it is essential to design robust composition and process scientifically justified [8].

This study's objective is to scrutinise the robust formula composition and process parameters to yield the best acceptable formulation in a statistically significant manner through the design of experiments using DOE software. The robust composition and process parameters retrieved through the operational buffer zone range obtained from the optimisation of several critical quality parameters linked to the overall acceptability of formulation.

\section{RESULTS AND DISCUSSION}

\subsection{Effect of tablet hardness and crospovidone concentration on in vitro DT, in vivo DT, and acceptability}

Preliminarily, the DOE study was evaluated for the significant effects among tablet hardness and crospovidone concentration on in vitro DT, in vivo DT, and acceptability based on inference from the halfnormal plot and pareto chart (Figure 1). The half-normal plot is used to choose the significant effects i.e. to select effects that are larger than among the effects studied. The pareto chart is to check for one or more significant effect that was not obvious from the half-normal plot. The palatability evaluation in healthy volunteers was evaluated using a questionnaire-based numerical scale through an approved study protocol [21-27]. The palatability intensity was derived from the outcome of bitterness intensity, sweetness intensity as part of initial taste (A), after taste (B), and through the outcome of mouthfeel (C). The extent of overall acceptability (unacceptable, acceptable, good, and excellent) is derived from the summation of A, B, and C. Overall, from the inference of half-normal plot and pareto chart, the crospovidone effect (A) shows a 
significant effect on in vitro DT, in vivo DT, and acceptability among the tablet hardness (B) and combined effect of crospovidone and hardness $(\mathrm{AB})$.
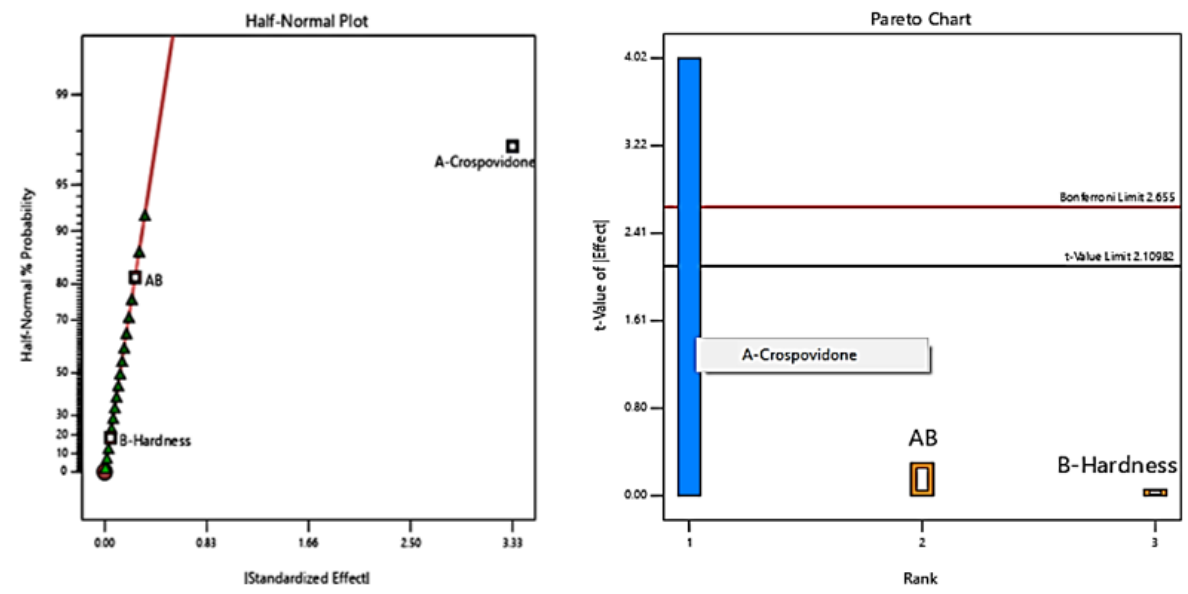

Figure 1. Half normal plot and pareto chart for tablet hardness, crospovidone effect on in vitro DT, in vivo DT, and acceptability.

\subsection{Three-dimensional scatter plot and correlation interpretation}

The three-dimensional scatter plot view has the potential application in interpreting a strong correlation among the multiple variables $[17,27]$. A three-dimensional scatter graph was plotted to infer the correlation between in vitro DT, in vivo DT, and overall acceptability related to crospovidone concentration. The outcome of the r-value of 0.979 (Figure 2a) indicates the existence of a strong correlation between in vitro DT and in vivo DT. The outcome of the r-value of 0.979 (Figure $2 \mathrm{~b}$ ) indicates a strong correlation between in vivo DT and acceptability.

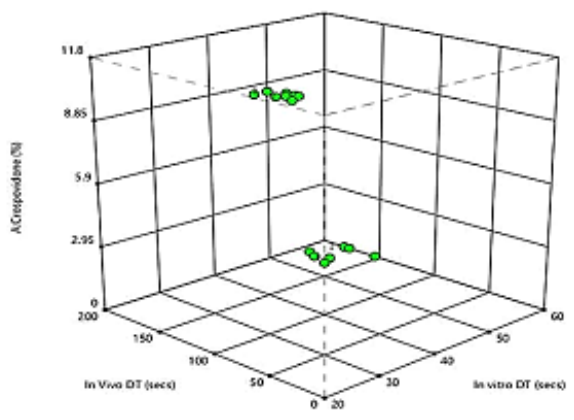

b.

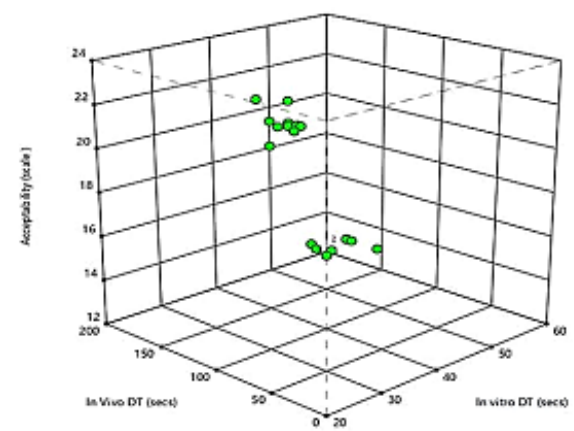

Figure 2. a. In vitro and in vivo correlation; b. In vivo and acceptability correlation.

\subsection{Verification of statistical significance of the DOE model used through analysis of variance (ANOVA)}

The most important consideration in the design of experiments is to ensure the statistical significance of output data and the model used to interpret it. The review of the analysis of variance (ANOVA) data (Table 1) output from the DOE software enables us to conclude on the statistical significance of data collected and the model used to generate the data [17]. The model F-value implies that the model selected for the DOE study is significant and there is a $0.01 \%$ chance that an F-value this large could occur due to noise. The P-values less than 0.0500 indicates model terms are significant. The lack of fit F-value implies the lack of fit is not significant relative to pure error and a non-significant lack of fit is good for the model selected for the DOE study. The fit statistics are the descriptive statistics that are used as a secondary check for the usefulness of the model. The coefficient of determination, R-squared $\left(R^{2}\right)$ measures the variation around the mean explained by the model. The predicated $R^{2}$ is in reasonable agreement with the adjusted $R^{2}$ i.e the difference is less than 0.2 as suggested by the DOE software. The adequate precision measures the signal to noise ratio and compares the range of predicted values at the design points to the average prediction error. A ratio greater than 4 indicates adequate 
model discrimination as suggested by the DOE software. As inferred from the ANOVA (Table 1), the observed ratio for adequate precision indicates that this model can be used to navigate this design space statistically and strong enough to be used for the optimisation.

Table 1. ANOVA for the selected factorial model.

\begin{tabular}{|c|c|c|c|c|c|c|c|c|}
\hline \multirow[b]{2}{*}{ Source } & \multirow{2}{*}{$\begin{array}{c}\text { F- } \\
\text { Value }\end{array}$} & \multirow[b]{2}{*}{ p-Value } & \multirow[b]{2}{*}{ Remarks } & \multicolumn{5}{|c|}{ Fit-Statistics } \\
\hline & & & & $\mathbf{R}^{3}$ & $\begin{array}{c}\text { Adjuste } \\
\mathrm{d} \mathrm{R}^{3}\end{array}$ & $\begin{array}{c}\text { Predicted } \\
\mathbf{R}^{3}\end{array}$ & $\begin{array}{c}\text { Adeq } \\
\text { Precision }\end{array}$ & $\begin{array}{r} \pm \\
\text { S.D. }\end{array}$ \\
\hline \multicolumn{9}{|c|}{ Response 1: In vitro DT } \\
\hline Model & 674.00 & $<0.0001$ & Significant & & & & & \\
\hline A-Crospovidone & 1344.98 & $<0.0001$ & Significant & & & & & \\
\hline B-Hardness & 3.01 & 0.1006 & $\begin{array}{c}\text { Not } \\
\text { significant }\end{array}$ & 0.9875 & 0.9861 & 0.9828 & 44.3520 & 2.07 \\
\hline \multicolumn{9}{|c|}{ Residual } \\
\hline Lack of Fit & 1.19 & 0.2914 & $\begin{array}{c}\text { Not } \\
\text { significant }\end{array}$ & & & & & \\
\hline \multicolumn{9}{|c|}{ Response 2: In vivo DT } \\
\hline Model & 151.46 & $<0.0001$ & Significant & & & & & \\
\hline A-Crospovidone & 302.86 & $<0.0001$ & Significant & & & & & \\
\hline B-Hardness & 0.0624 & 0.8507 & $\begin{array}{c}\text { Not } \\
\text { significant }\end{array}$ & 0.9469 & 0.9406 & 0.9265 & 20.3835 & 0.42 \\
\hline \multirow{2}{*}{\multicolumn{9}{|c|}{$\begin{array}{c}\text { Not } \\
\text { significant }\end{array}$}} \\
\hline & & & & & & & & \\
\hline \multicolumn{9}{|c|}{ Response 3: Acceptability } \\
\hline Model & 1771.12 & $<0.0001$ & Significant & & & & & \\
\hline A-Crospovidone & 3539.12 & $<0.0001$ & Significant & & 0.9947 & 0.9934 & 70.7341 & 0.36 \\
\hline B-Hardness & 3.12 & 0.0952 & Significant & 0.9952 & & & & \\
\hline & Residua & & & & & & & \\
\hline Lack of Fit & 3.60 & 0.0760 & $\begin{array}{c}\text { Not } \\
\text { significant }\end{array}$ & & & & & \\
\hline
\end{tabular}

\subsection{Optimisation and confirmation of DOE study}

After verification of the statistical significance of the DOE model selected, further DOE study was optimised using RSM through a numerical and graphical model to arrive at a design space with a maximised acceptable response in terms of maximising the overall acceptability of designed flexible dispersible tablets $[17,24,27]$. The optimisation exercise was carried out using the numerical and graphical model to optimise the input parameters (crospovidone concentration in combination with tablet hardness) to maximise the acceptance criteria placed on each of the responses. The optimisation using a numerical model is to find the most favourable set of conditions that will meet the goals. The outcome from the numerical model (Figure 3) interpreting that, the targeted responses namely in vitro DT (Target: NMT 30 secs), in vivo DT (Target: NMT 60 secs), and acceptability (Target: $\geq 21$ numerical value) will meet the targetted acceptance criteria with crospovidone concentration $>$ $8.85 \% \mathrm{w} / \mathrm{w}$ of targetted tablet weight along with irrespective of tablet hardness range selected for the study. As per software recommendations, the desirability of attaining close to 1.0 is not a criterion. However, the volume of the design space is the most desirable ones.

In continuation of numerical model optimisation, graphical model optimisation was carried out to show the volume where maximised response outcomes can be found based on numerical optimisation [17]. Interval estimates can be added to the graphical optimisation plot to understand the impact of uncertainty on achieving the optimisation goals. Regions that do not fit the target optimisation criteria are shaded grey and regions with yellow shade indicate the entire range of intervals meet the specified criteria (Figure 4). Finally, it confirmed that combination of crospovidone concentration of about $11.7 \% \mathrm{w} / \mathrm{w}$ of targetted tablet weight and tablet hardness range of $10-15 \mathrm{Kp}$ against the crospovidone concentration $10.89 \% \mathrm{w} / \mathrm{w}$ will able to repeatability achieve the targetted response/acceptance criteria at alpha 0.05 one-sided confidence interval i.e. at $95 \%$ confidence level. Statistical significance for the confirmed study for the input factors using the graphical model inferred from Table 2. 


\section{CONCLUSION}

The present study outcome from quality by design approach using design-expert software demonstrated its ability to evaluate and to recommend the optimum formula composition and process condition in a single set of experimental run compared to the traditional method of experimental run. The derived optimum formula component i.e. optimum crospovidone concentration $\left(\mathrm{X}_{1}\right)$ and process condition i.e. optimum tablet hardness range $\left(X_{2}\right)$, tend to assist in maximising the user acceptance of the designed ceftibuten flexible dispersible tablet in a very statistically significant and economical manner.
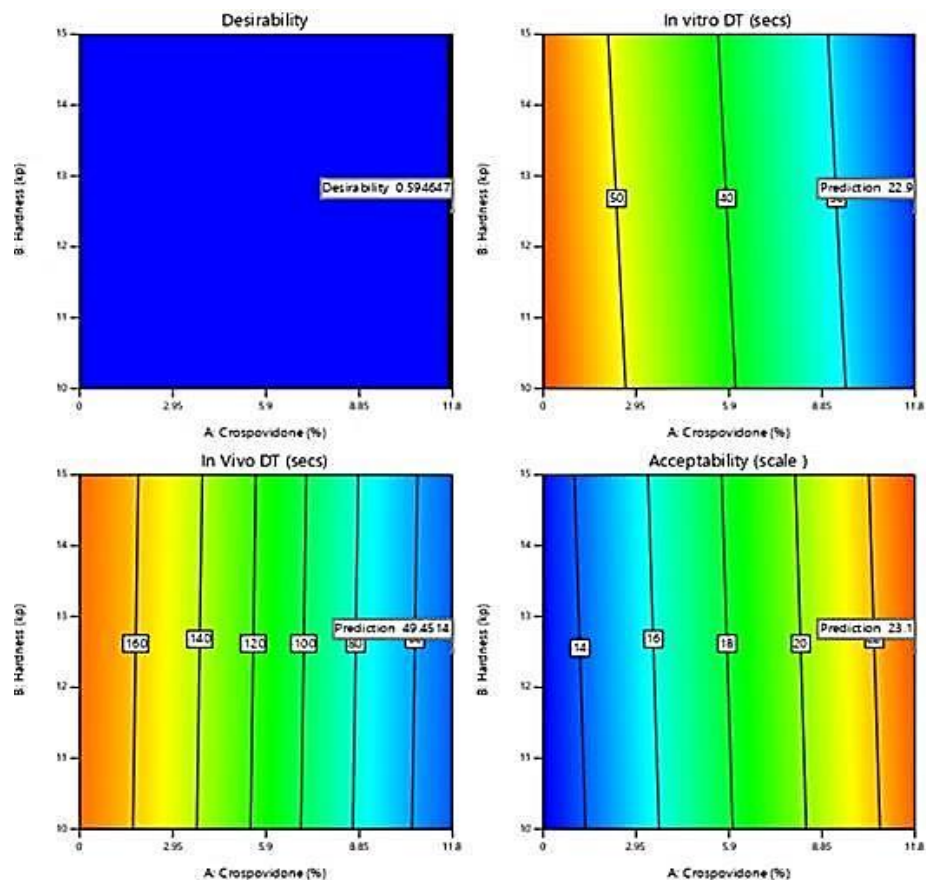

Figure 3. Inference of optimum condition through a contour plot using a numerical model.

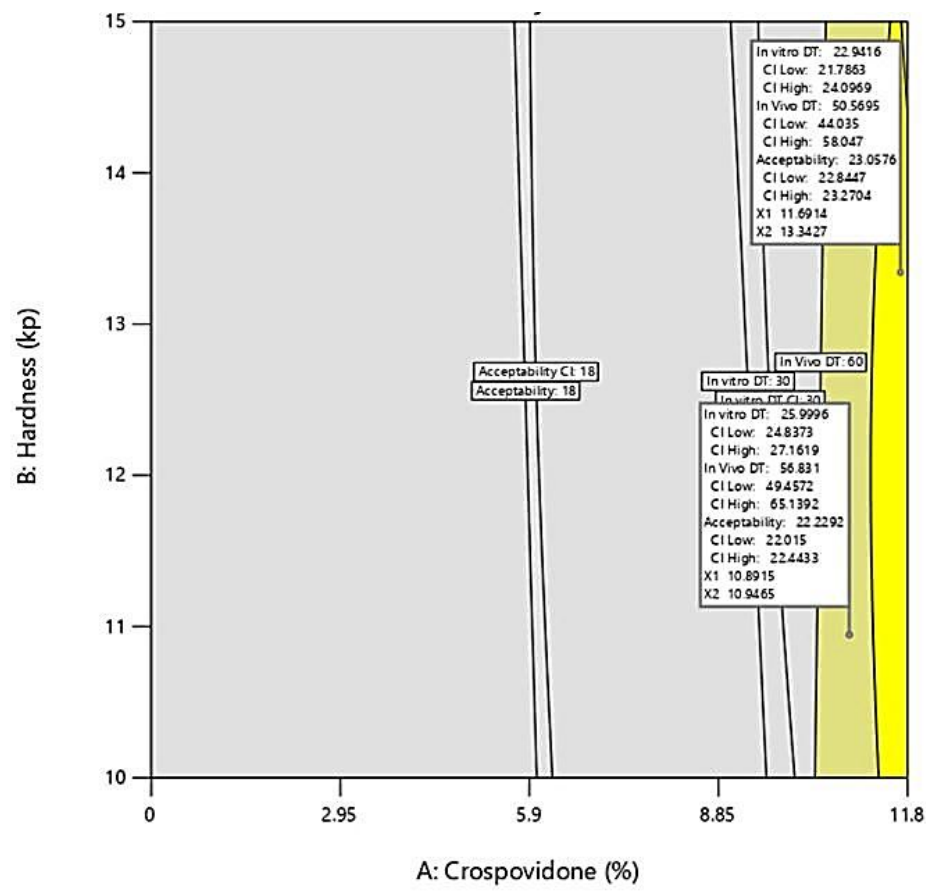

Figure 4. The outcome of optimized factors through overlay plot.

\section{MATERIALS AND METHODS}

\subsection{Drug substance and excipients}


Ceftibuten was obtained from Orchid Pharma Ltd., India. Silicified microcrystalline cellulose was obtained from FMC Corporation, Pennsylvania, and JRS Pharma, USA. Crospovidone Type A was obtained from Ashland, Texas. Magnesium stearate was obtained from Avantor, USA. Aspartame was obtained from Ajinomoto, Japan. The banana flavour was obtained from Firmenich Aromatics (I) Pvt Ltd., India.

Table 2. Design optimisation and confirmation using a graphical model.

\begin{tabular}{|c|c|c|c|c|c|c|}
\hline \multicolumn{3}{|c|}{ Optimization Input } & \multicolumn{2}{|c|}{$\begin{array}{c}\text { Optimization Confirmation } \\
\text { (from overlay plot) }\end{array}$} & \multicolumn{2}{|c|}{$\begin{array}{c}\text { Statisitical Significance } \\
\text { of Optimisation ( } p \text {-value) }\end{array}$} \\
\hline $\begin{array}{c}\text { Response } \\
\text { Parameters } \\
\text { for } \\
\text { Optimization } \\
\end{array}$ & $\begin{array}{l}\text { Range } \\
\text { Limit }\end{array}$ & $\begin{array}{c}\text { Criteria used } \\
\text { during } \\
\text { Optimization }\end{array}$ & Input Factors & $\begin{array}{c}\text { Response } \\
\text { Output } \\
( \pm \text { S.D. })\end{array}$ & A (crospovidone) & $\begin{array}{c}\text { B } \\
\text { (Tablet } \\
\text { Hardness) }\end{array}$ \\
\hline $\begin{array}{l}\text { In vitro DT } \\
\text { (secs) }\end{array}$ & $\begin{array}{c}21 \text { to } \\
30\end{array}$ & & & $23(2.0)$ & $<0.0001$ & 0.1006 \\
\hline $\begin{array}{l}\text { In vivo DT } \\
\text { (secs) }\end{array}$ & $\begin{array}{c}35 \text { to } \\
60\end{array}$ & One-sided & $\begin{array}{c}X_{1}=11.7 \\
\text { (Crospovidone) }\end{array}$ & $50(12.5)$ & $<0.0001$ & 0.8507 \\
\hline $\begin{array}{c}\text { Acceptability } \\
\text { (numerical } \\
\text { scale) }\end{array}$ & $\begin{array}{l}18 \text { to } \\
25\end{array}$ & $\begin{array}{l}\text { interval at } \\
\text { Alpha } 0.05\end{array}$ & $\begin{array}{c}\mathrm{X}_{2}=13 \\
\text { (Tablet hardness) }\end{array}$ & $23(0.3)$ & $<0.0001$ & 0.0952 \\
\hline
\end{tabular}

\subsection{Pre-design of experiments}

Before initiating the DOE, it is necessary to generate knowledge space about critical drug product quality factors through brainstorming sessions with the help of risk management tools. Among the several risk management tools, the cause and effect diagram or fishbone diagram assessment tool (Figure 5) [11,12] used to fish-out the factors for DOE study from among the CQAs affecting drug product quality of intended flexible dispersible tablets design linked to the overall acceptability. From the outcome of the brainstorming session and from the extent of critical nature as described in Table 3 [9-22], the factor variables (input) are prioritized to understand for a statistically significant effect on relevant response variables (output) among the CQAs identified. From the outcome of justification on critical nature among the CQAs as described in Table 3 , in vitro disintegration time (in vitro DT), in vivo disintegration time (in vivo DT), and palatability is prioritized as response variables linked to the overall acceptability of intended dosage form design. Disintegrant concentration and tablet hardness are considered as input variables linked to the impact on response variables.

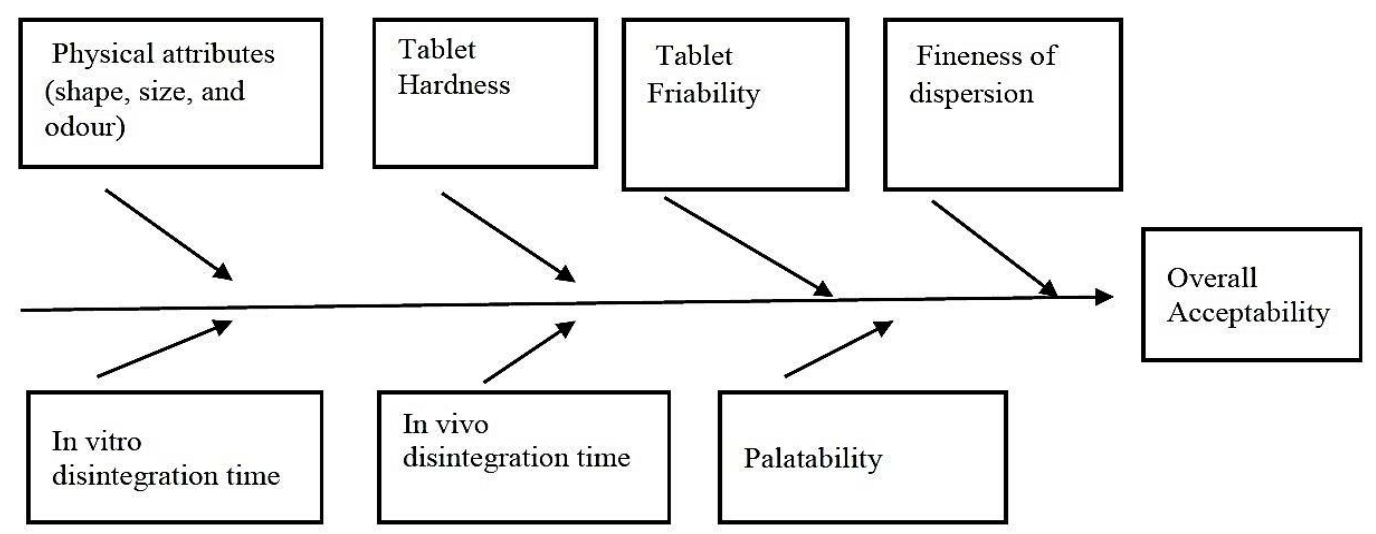

Figure 5. Cause and effect diagram (Ishikawa or fishbone diagram).

\subsection{Formulation of dispersible tablets}

The powder flow nature of the drug substance, ceftibuten dihydrate through funnel found not continuous and required intermittent tapping to initiate flow. Due to the poor flow nature and due to the high drug loading content of active $(72.52 \% \mathrm{w} / \mathrm{w})$ in the intended dosage form design, a dry granulation approach using roll compaction is considered for manufacturing. The components excluding lubricant co-sifted through \#30 mesh, mixed, lubricated, and compacted using roll compactor. The resultant granules were subjected to sizing, lubrication, and compressed using suitable tooling as per targeted tablet weight. The prototype compositions are tabulated in Table 4 .

\subsection{Evaluation of dispersible tablets}




\subsubsection{In vitro DT (in-house method)}

The in vitro DT (in-house method) was developed and measured by placing 1 tablet in $20 \mathrm{ml}$ of water taken in a glass beaker of $50 \mathrm{ml}$ capacity maintained at $37^{\circ} \mathrm{C}$, the time taken for tablet complete disintegration was measured.

Table 3. Justification for critical quality attributes of dosage form design and acceptance criteria for the DOE factors.

\begin{tabular}{|c|c|}
\hline $\begin{array}{l}\text { Drug product quality } \\
\text { attributes }\end{array}$ & Target \\
\hline $\begin{array}{l}\text { Physical } \\
\text { Attributes }\end{array}$ & $\begin{array}{l}\text { Not more than (NMT) } 22 \mathrm{~mm} \text { in } \\
\text { any dimension. }\end{array}$ \\
\hline
\end{tabular}

Odour No unpleasant odour N No

Tablet Hardness

In vitro disintegration time (using apparatus recommended by official monographs).

In-vitro disintegration

time (In-House method).

Fineness of dispersion (In House method).

In vivo disintegration time

NMT 60 seconds

NMT 30 seconds Yes

Is this Justification
Critical?

Is this

No

(1)

\author{
Tablet size and shape correlates to \\ swallowing difficulty as a whole since the \\ dosage form design is a dispersible \\ formulation intended either as orally \\ dispersible or dispersible in water before \\ administration. Therefore the size \& shape \\ may not be critical. However, to ensure \\ patient acceptability, the size of tablets \\ restricted as per US-FDA Guidance for \\ industry on Size, Shape, and Other \\ Physical Attributes of Generic Tablets and \\ capsules. \\ In general, a noticeable odour is not directly \\ linked to safety and efficacy, but the \\ unpleasant odour can affect patient \\ acceptability. For this intended dosage form \\ design, neither the drug substance nor the \\ excipients have an unpleasant odour. No \\ organic solvents will be used in the drug \\ product manufacturing process.
}

a. In vitro disintegration time: $\quad$ Yes
NMT $30 \mathrm{sec}$
b. Friability: NMT
$1.0 \% \mathrm{w} / \mathrm{w}$

a. To ensure rapid disintegration when placed upon the tongue.

b. A target of NMT $1.0 \%$ weight loss is set according to the compendia requirements set according to the compendia equirements to minimize post-marketing complaints. This quality attribute can be ffectively controlled through an appropriate hardness range.

To ensure rapid disintegration when placed upon the tongue.

To ensure complete disintegration when placed upon the tongue under static condition.

Yes" $\quad$ To ensure free from choking hazard possibility.

a. To assure a low impact on patient acceptability.

b. Based on official monograph (USP42-

NF37) specification on In-vitro disintegration time of NMT 60 seconds for orally disintegrating tablets.

To achieve better patient compliance towards intended dosage form design.
Numerical scale ranging from acceptable (score $\geq 18-20$ ), good (score $\geq 21-24$ ) to excellent (score $\geq 25$ ) during palatability study Yes based on a questionnaire based numerical scale

\# considered as a secondary line of information as supportive data, therefore, this will not be investigated in detail as part of the DOE. 


\subsubsection{Fineness of dispersion (in-house method)}

The fineness of dispersion (in-house method) was developed by modification of the pharmacopeial method by replacing the sieve size and volume of the testing medium. The fineness of dispersion was measured by placing 1 tablet in $20 \mathrm{ml}$ of water taken in a glass beaker of $50 \mathrm{ml}$ capacity maintained at $37^{\circ} \mathrm{C}$. After 30 seconds the beaker was gently shaken, and the resultant dispersion passed through a sieve No. 30 .

\subsubsection{In vivo DT and palatability study}

All the volunteers who provided written informed consent participated in the study. The volunteers received no remuneration for participating in the study. The in vivo disintegration and palatability study was performed in healthy volunteers (n: 10; age range:13-80 years) after obtaining ethics committee clearance (ECR/306/Indt/TN/2019). Before the study, the volunteers were subjected to the screening test to ensure the ability of the volunteers in recognizing the nature and intensity of three different concentrations of bitterness, sweetness, and three samples of neutral taste based on verbal (descriptive) judgment. The screened volunteers were involved in the study after appropriate training [26].

Table 4. Prototype composition.

\begin{tabular}{|c|c|c|c|}
\hline Prototype Trial & P1 & $\mathbf{P 2}$ & P3 \\
\hline Ceftibuten dihydrate & 435.12 & 435.12 & 435.12 \\
\hline Silicified microcrystalline cellulose & 152.88 & 104.88 & 81.88 \\
\hline Crospovidone Type A & - & 48.00 & 71.00 \\
\hline Aspartame & 3.00 & 3.00 & 3.00 \\
\hline Banana Flavour & 3.00 & 3.00 & 3.00 \\
\hline Magnesium stearate & 6.00 & 6.00 & 6.00 \\
\hline Target Tablet weight (mg) & 600.0 & 600.0 & 600.0 \\
\hline Tooling dimension (mm) & \multicolumn{3}{|c|}{$17.9 \times 7.8$} \\
\hline Tablet Hardness: At $10 \mathrm{Kp}$ & \multirow[b]{2}{*}{0.63} & \multirow[b]{2}{*}{0.55} & \multirow[b]{2}{*}{0.43} \\
\hline Tablet Friability (\%) at $100 \mathrm{rpm}$ & & & \\
\hline In vitro disintegration time (seconds) & \multirow[b]{2}{*}{$65 \pm 0.9$} & \multirow[b]{2}{*}{$26 \pm 0.9$} & \multirow[b]{2}{*}{$24 \pm 0.5$} \\
\hline $\begin{array}{l}(\mathrm{n}=3) \pm \text { S.D. } \\
\text { (using apparatus recommended by } \\
\text { official monographs without disc) }\end{array}$ & & & \\
\hline $\begin{array}{l}\text { In vitro disintegration time in } 20 \mathrm{ml} \text { of } \\
\text { water (seconds) }(\mathrm{n}=3) \pm S \text {.D. (In-house } \\
\text { method) }\end{array}$ & \multirow{3}{*}{$\begin{array}{l}\text { Residue on } \\
\text { \#30 mesh }\end{array}$} & $23 \pm 1.2$ & $22 \pm 1.2$ \\
\hline $\begin{array}{l}\text { Fineness of dispersion } \\
\text { (In-House method) }(n=3)\end{array}$ & & $\begin{array}{l}\text { No residue } \\
\text { on \#30 mesh }\end{array}$ & $\begin{array}{l}\text { No residue } \\
\text { on \#30 mesh }\end{array}$ \\
\hline Tablet Hardness: At $15 \mathrm{Kp}$ & & & \\
\hline Tablet Friability (\%) at $100 \mathrm{rpm}$ & 0.30 & 0.27 & 0.29 \\
\hline $\begin{array}{l}\text { In vitro disintegration time (seconds) } \\
\text { (seconds) }(\mathrm{n}=3) \pm S . \mathrm{D} \text {. } \\
\text { (using apparatus recommended by } \\
\text { official monograph without discs) }\end{array}$ & $90^{\mathrm{a}} \pm 0.8$ & $27 \pm 0.5$ & $25 \pm 0.5$ \\
\hline $\begin{array}{l}\text { In vitro disintegration time in } 20 \mathrm{ml} \\
\text { of water (In-House method) (seconds) }\end{array}$ & $60 \pm 0.8$ & $23 \pm 1.2$ & $22 \pm 1.2$ \\
\hline $\begin{array}{l}(n=3) \\
\text { Fineness of dispersion } \\
\text { (In-House method })(n=3)\end{array}$ & $\begin{array}{l}\text { Residue on } \\
\# 30 \text { mesh }\end{array}$ & $\begin{array}{l}\text { No residue } \\
\text { on \#30 mesh }\end{array}$ & $\begin{array}{l}\text { No residue } \\
\text { on \#30 mesh }\end{array}$ \\
\hline
\end{tabular}


Before the test, volunteers rinsed their oral cavities with potable water, each dispersible tablet placed on their tongues and allows to disintegrate in their oral cavity. Volunteers were directed to move the tablet against the upper part of the mouth with their tongue without biting the tablet. After the last noticeable tablet lumps disintegrated, the time was recorded immediately. The resultant disintegrated dispersion hold for 30 seconds in their oral cavity to feel the intensity of initial taste and mouthfeel through verbal judgement followed by scoring on a scale. The remnants of dispersion spit out, waited for 60 seconds to feel the intensity after taste and mouthfeel through verbal judgement followed by scoring on a scale. The volunteers were allowed to rinse their oral cavity with potable water to ensure get rid of the intensity of previous test samples before moving on to the next test samples [22-27].

\subsection{Design of Experiments}

Based on knowledge space generated from the preliminary prototype trial, the crospovidone concentration and hardness range were decided for DOE design. DOE design was carried out using DesignExpert ${ }^{\circledR}$ version 12 software from Stat-Ease, Inc. Two-level full factorial with replicates design was selected. The designed factors and responses are tabulated in table 5. The primary objective to understand the statistically significant effects of crospovidone concentration and tablet hardness range on targeted responses and further optimised to maximise the overall acceptability through the selection of the best of components. As per software recommendation, the power of design should be approximately $80 \%$ or greater for the effects under consideration. The recommended design of experiments by the software is tabulated in table 6 .

Table 5. The designed DOE factors, responses, and power.

\begin{tabular}{|c|c|c|c|c|c|c|c|c|c|}
\hline \multicolumn{5}{|c|}{ Factors } & \multicolumn{3}{|c|}{ Responses } & \multirow[t]{2}{*}{$\begin{array}{c}\text { Power } \\
\text { for A }\end{array}$} & \multirow[t]{2}{*}{$\begin{array}{c}\text { Power } \\
\text { for B }\end{array}$} \\
\hline Name & Units & Type & Low & High & Name & Units & Type & & \\
\hline $\begin{array}{l}\text { Crospovidone } \\
\text { (A) }\end{array}$ & $\%$ & Numeric & 0 & 11.8 & In vitro $\mathrm{DT}$ & $\begin{array}{l}\text { Seconds } \\
\text { (secs) }\end{array}$ & Numeric & $99.9 \%$ & $99.9 \%$ \\
\hline Hardness & Kilopond & Numeric & 10 & 15 & $\begin{array}{l}\text { In vivo } \\
\text { DT }\end{array}$ & $\begin{array}{l}\text { Seconds } \\
\text { (secs) }\end{array}$ & Numeric & $99.9 \%$ & $99.9 \%$ \\
\hline (B) & & & & & Acceptability & - & Numeric & $99.9 \%$ & $99.9 \%$ \\
\hline
\end{tabular}

Table 6. The recommended experimental design by the software and the updated responses.

\begin{tabular}{cccccc}
\hline $\begin{array}{c}\text { Run } \\
\text { number }\end{array}$ & $\begin{array}{c}\text { Factor } \mathbf{1} \\
\text { A: Crospovidone } \\
\mathbf{( \% )}\end{array}$ & $\begin{array}{c}\text { Factor 2 } \\
\text { B: Hardness } \\
\mathbf{( K p )}\end{array}$ & $\begin{array}{c}\text { Response 1 } \\
\text { In vitro DT } \\
\mathbf{( s e c s )}\end{array}$ & $\begin{array}{c}\text { Response 2 } \\
\text { In vivo DT } \\
\text { (secs) }\end{array}$ & $\begin{array}{c}\text { Response 3 } \\
\text { Acceptability } \\
\text { (Numerical scale) }\end{array}$ \\
\hline 1 & 11.8 & 10 & 22 & 35 & 23 \\
2 & 0 & 15 & 53 & 165 & 13 \\
3 & 0 & 10 & 60 & 180 & 13 \\
4 & 11.8 & 10 & 23 & 60 & 22 \\
5 & 11.8 & 10 & 23 & 45 & 23 \\
6 & 0 & 10 & 60 & 180 & 13 \\
7 & 11.8 & 10 & 24 & 40 & 23 \\
8 & 0 & 10 & 60 & 150 & 23 \\
9 & 11.8 & 15 & 22 & 48 & 23 \\
10 & 11.8 & 10 & 24 & 43 & 13 \\
11 & 0 & 15 & 55 & 170 & 24 \\
12 & 0 & 10 & 55 & 170 & 24 \\
13 & 11.8 & 15 & 21 & 60 & 13 \\
14 & 11.8 & 15 & 23 & 45 & 13 \\
15 & 0 & 15 & 60 & 175 & 13 \\
16 & 0 & 15 & 54 & 180 & 13 \\
17 & 0 & 10 & 55 & 190 & 23 \\
18 & 0 & 15 & 55 & 170 & 23 \\
19 & 11.8 & 15 & 24 & 50 & \\
20 & 11.8 & 15 & 23 & 60 & \\
\hline
\end{tabular}


Acknowledgements: This review did not receive any specific grant from funding agencies in the public, commercial, or not- for-profit sectors.

Author contributions: Concept - S.P.G.; Design - S.P.G.; Supervision - S.P.G., S.R., A.K.; Resources - S.P.G.; Materials - S.P.G.; Data Collection and/or Processing - S.P.G.; Analysis and/or Interpretation - S.P.G.; Literature Search - S.P.G.; Writing - S.P.G., S.R., A.K.; Critical Reviews - S.P.G., S.R., A.K.

Conflict of interest statement: The authors declared that there is no conflict of interest in this study.

Ethics committee approval: All experiments conducted in this study were approved by ethics committee of Periyar College of Pharmaceutical Sciences with the approval number of ECR/306/Indt/TN/2019 on June 6 2019.

\section{REFERENCES}

[1] Sharrif Z, Kirby D, Missaghi S, Rajabi-Siahboomi A, Maidment I. Patient-Centric Medicine Design: Key Characteristics of Oral Solid Dosage Forms that improve Adherence and Acceptance in Older People. Pharmaceutics. 2020; 12(10): 1-15. [CrossRef]

[2] Govindan S P, Senthamarai R, Anbarasu K. Design of Flexible Dispersible Tablet with high drug loading using quality by Design: Proof of Concept study using third generation Cephalosporins Model Drug. Research J Pharm Tech. 2021; 14(2): 705-714.

[3] Walsh J, Ranmal S R, Ernest T B, Liu F. Patient acceptability, safety and access: A balancing act for selecting ageappropriate oral dosage forms for paediatric and geriatric populations. Int J Pharm. 2018; 536(2): 547-562. [CrossRef]

[4] Logrippo S, Ricci G, Sestili M, Cespi M, Ferrara L, Palmieri G F, Ganzetti R, Bonacucina G, Blasi P. Oral drug therapy in elderly with dysphagia: between a rock and a hard place. Clin Interv Aging. 2017; 12: 241-251.

[5] Orubu E SF, Tuleu C. Medicines for children: flexible solid oral formulations. Bull World Health Organ. 2017; 95: 238240. [CrossRef]

[6] Hoppu, K. Time to change the paradigm of children's medicines from liquid formulations to flexible solid oraldosage forms. Ceylon Med J. 2016; 61(3): 93-95. [CrossRef]

[7] Liu F, Ranmal S, Batchelor H K, Gul M O, Ernest T B, Thomas I W, Flanagan T, Tuleu C. Patient-Centred Pharmaceutical Design to Improve Acceptability of Medicine: Similarities and Differences in Pediatric and Geriatric Populations. Drugs. 2014; 74(16):1871-1889. [CrossRef]

[8] Govindan S P, Senthamarai R, Anbarasu K. Refrigeration and the Shelf Life of Oral Cephalosporin Powder for Suspension Dosage Form: Review and Proposal. Int. J Emerg Technol. 2019; 10(2).376-383.

[9] International Conference on Harmonisation (ICH), 2009. ICH Harmonised Tripartite Guideline: Pharmaceutical Development Q8 (R2). https://database. ich.org/sites/default/files/Q8_R2_Guideline.pdf (accessed June 30, 2020).

[10] Quality by Design for ANDAs: An Example for Immediate-Release Dosage Forms.

https://www.fda.gov/media/83664/download (accessed June 30, 2020).

[11] Dhoot A S, Fernandes G J, Naha A, Rathnanand M, Kumar L. Design of Experiments in Pharmaceutical Development. Pharm Chem J. 2019; 53(8): 730-735.

[12] Sangshetti J N, Deshpande M, Arote R, Zaheer Z, Shinde D B. Quality by design approach: Regulatory need. Arabian J Chem. 2017; 10(2): S3412-S3425. [CrossRef]

[13] Tablet Scoring: Nomenclature, Labeling, and Data for Evaluation. https://www.fda.gov/media /81626/download (accessed June 30, 2020).

[14] Guidance for Industry Orally Disintegrating Tablets. https://www. fda.gov/media/70877/download (accessed June 30, 2020).

[15] Guidance for Industry Size, Shape, and other Physical Attributes of Generic Tablets and Capsules. https://www.fda.gov/media/87344/download (accessed June 30, 2020).

[16] Bircan Y, Çomoğlu T. Formulation technologies of orally fast disintegrating tablets. Marmara Pharm J. 2012; 16: $77-$ 81.

[17] Handbook for Experimenters Version 11.01. https://cdnm.statease.com/pubs/handbk_for_exp_sv.pdf (accessed June 7, 2019).

[18] Ceftibuten. https://www.accessdata.fda.gov/scripts /cder/dissolution/dsp_SearchResults.cfm (accessed June 7, 2019). 
[19] Ali T, Ediz Y, Gülcin T. Ceftibuten Capsule Formulations. European Patent 3031450 A1; 2016 (accessed June 7, 2019).

[20] Cedax® (ceftibuten capsule) and (ceftibuten for oral suspension). https://www.accessdata.fda.gov/drugsatfda_docs/label/2009/050685s011,050686s014IbI.pdf (accessed on June 7, 2019).

[21] Belissa E, Vallet T, Caget S L, Chevallier A, Chedhomme F X, Abdallah F, et al. Acceptability of oral liquid pharmaeutical products in older adults: palatability and swallowability issues. BMC Geriatrics. 2019; 19(344): 2-9. [CrossRef]

[22] European Medicines Agency (EMEA), 2012. Presentation-acceptability and palatability- methods available for assessment. https://www.ema.europa.eu/en/documents/presentation/presentation-acceptability-palatabilityMethods-available-assessment_en.pdf (accessed May 3, 2020).

[23] Brniak W, Jachowicz R, Pelka P. The practical approach to the evaluation of methods used to determine the disintegration time of orally disintegrating tablets (ODTs). Saudi Pharm J. 2015; 23: 437-443. [CrossRef]

[24] Yoshita T, Uchida S, Namiki N. Clinical Disintegration Time of Orally Disintegrating Tablets Clinically Available Japan in Healthy Volunteers. Biol. Pharm. Bull. 2013; 36(9): 1488-1493.

[25] Kim J-II, Cho S-Min, Cui J-H, Cao Q-Ri, Oh E, Lee B-J. In Vitro and in Vivo Correlation of disintegration and bitter Taste masking using orally disintegrating tablet containing ion exchange resin-drug complex. Int J Pharm. 2013; 455: 31-39. [CrossRef]

[26] Callejo M J, Kostiuk-V Eugenia-M, Quijano-M R. Selection, training and validation of a sensory panel for bread analysis: Influence of cultivar on the quality of breads made from common wheat and spelt wheat. J Cereal Sci. 2015; 61: 55-62. [CrossRef]

[27] Ranmal S R, O’Brien F, Lopez F, Ruiz F, Orlu M, Tuleu C, et al. Methodologies for assessing the acceptability of oral formulations among children and older adults : a systematic review. Drug Discov Today. 2018; 23(4): 830-847. [CrossRef]

This is an open access article which is publicly available on our journal's website under Institutional Repository at http://dspace.marmara.edu.tr. 